\title{
Ecology Treatment of Printed Circuit Boards
}

\author{
Dagmar Janáčová ${ }^{1, *}$, Jiří Ǩrenek ${ }^{1}$, Miluše Vítečková ${ }^{2}$ and Vladimír Vašek ${ }^{1}$ \\ 1 Tomas Bata Univerzity in Zlín, Faculty of Applied Informatics, nám. T.G.Masaryka 5555, 760 01 Zlín, Czech Republic \\ ${ }^{2}$ VSB - Technical University of Ostrava, Faculty of Mechanical Engineering, 17.listopadu 15, 70833 Ostrava - Poruba, Czech Republic
}

\begin{abstract}
This contribution contents one possibility of $\mathrm{PCB}$ separation due to the temperature due to the different thermal expansion of the metal path and the plastic from which the boards are made. The separation of metal and plastic may occur due to temperature changes if the temperature difference is sufficient. We have carried out a study of printed circuit board production so we can choose the appropriate path of separation. Furthermore, we determined the shear stress size required to tear the conductive copper paths from the epoxy resin. The temperature field in a two-layer board was modelled in simulation software FEMLAB and Pro/ENGINEER. From the simulated temperature field simulations, conclusions can be drawn that accurately describe the condition and characteristics of materials subjected to heat shock. In our own experiments, we used several ways to heat PCBs. After using the mechanical separation of the components, they were dropped from the PCB. Mechanical separation was also used when removing conductive paths. This separation is effective, but in the newer types of PCBs, the cyclical effects of thermal shock have to be applied to the separation of copper paths. Experimental tests have demonstrated the viability of the proposed method. The proposed method of recycling could lead to industrial use in case consistent sorting of waste electrical and electronic parts of old items.
\end{abstract}

Keywords: Shear stress, thermal shock, stress, linear expansion, electronic waste, printed circuit board (PCB), recycling, conductive paths, Pro/ENGINEER, COMSOL Multiphysics.

\section{Introduction}

In recent years with the development of consumer electrics the recycling of electric waste has become a necessity the due to the lowering prices of electrics we experience its massive consumption as well as decrease of its lifetime. Retired electrics normally used to end in the solid and hazardous waste landfills. Because these products contain many valuable components, but also materials that are harmful to the environment, we have focused our work on the possibilities of reuse of the retired electric waste, originating mainly from computing technologies, as a source of valuable raw materials.

Electric waste is currently the fastest growing type of the waste. Globally it now constitute up to $5 \%$ of weight of the solid domestic waste which is almost as much as plastic packaging. In the European Union countries, where households annually produce about 8 million tons of electric waste, the electric waste is growing at a rate of 3-5\% per year, almost three times faster than the total waste volume. Developing countries even assume that their electric waste production will triple by 2010. Experts estimate that in line with the growth in sales of electrics the European Union will have to cope with almost 11 million tons of the electric waste just in 2020. Ten years later the annual production will rise to almost 14 mil. tons. We must add to this another approximately three million tons of the electric waste originating from organizations and companies $[1,2,4]$. 


\section{Linear expansion of $\mathrm{PCB}$ materials}

The following figure shows the status of materials during the temperature change. It is evident that the expansion of the material 1 is much smaller than in the material 2. This is due to the different coefficients of thermal expansion of both materials. We used this property to derive a formula for the calculation of the resulting shear stress which is needed for separation of the conductive paths and plastic materials from the PCB [4].

(1)

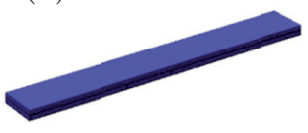

(3)

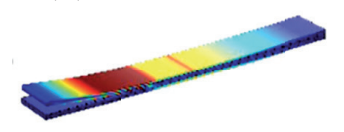

(4)
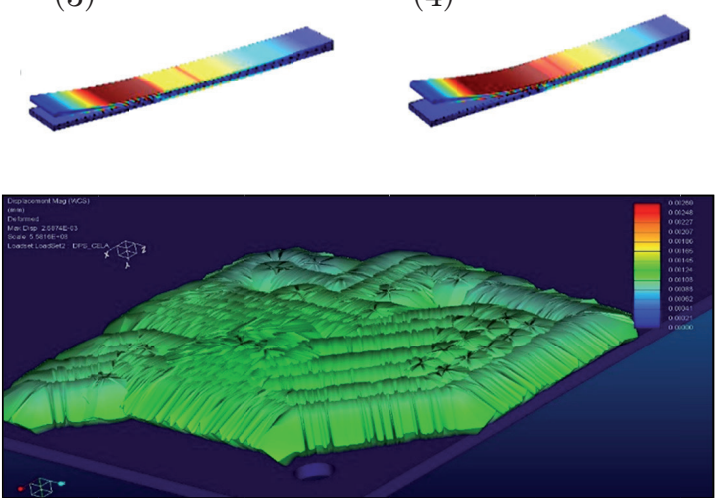

Fig. 1: Linear expansion of materials during heating 1,2,3,4, longitudinal display in Pro / ENGINEER software (down).

To calculate the amount of shear stress needed to split the two boards we used the Hook's law.

$\sigma=E \cdot \varepsilon$

where $\sigma$ - the resulting shear stress $[\mathrm{Pa}], E$ modulus of elasticity $[\mathrm{Pa}], \boldsymbol{\varepsilon}$ - the relative elongation [-].

In the final equation it is necessary to take into account the thermal expansion of solid objects.

$l=l_{o}(\alpha \Delta T+1)$

where $\alpha$ - the coefficient of linear expansion $\left[\mathrm{K}^{-1}\right]$, $\Delta T$ - the temperature difference $[\mathrm{K}], l_{0}$ - the original length of the material [m].

By modifying and merging the two equations we get the following equation for calculation of the shear stress of one plate.
$\sigma=E \alpha \Delta T$

Resultant force $F_{T}$ can be specified

$F_{T}=\left(\sigma_{1}-\sigma_{2}\right) S_{j}$

Where $F_{T}$ - a resultant force $[\mathrm{N}], \sigma_{1}$ - tensile stress of the first material $[\mathrm{Pa}], \sigma_{2}$ - tensile stress of the second material $[\mathrm{Pa}], S_{j}$ - the contact surface of both materials $\left[\mathrm{m}^{2}\right]$.

This force must be greater than the allowable shear stress for the materials, which gives the following relationship:

$\frac{F_{T}}{S_{j}}>\tau_{s}$

where $\tau_{s}$ - the maximum allowable shear stress of the material [MPa].

For the calculation we selected the combination of epoxy resin and copper [7].

Calculation shows the size of the force in dependence on change of the temperature which is required to peel the copper surface paths from the epoxy resin. The required shear stress for separation of Cu path from PCB is $109^{\circ} \mathrm{C}$.

Table 1: Mechanical properties of materials [7].

\begin{tabular}{|l|l|l|}
\hline & FR4 & Copper \\
\hline$E(\mathrm{~Pa})$ & $22 \cdot 10^{9}$ & $11 \cdot 10^{10}$ \\
\hline$\alpha\left(\mathrm{K}^{-1}\right)$ & $18 \cdot 10^{-6}$ & $17 \cdot 10^{-6}$ \\
\hline
\end{tabular}

\section{Mathematic Model of Non-stationary Temperature Field of Two Layers Folder}

For describing heating and cooling process of two layers folder we used following mathematic model [5]:

$\frac{\partial t_{1}}{\partial \tau}(x, \tau)=a_{1} \frac{\partial^{2} t_{1}}{\partial x^{2}}(x, \tau), \quad \tau>0,0<x<b$

$\frac{\partial t_{2}}{\partial \tau}(x, \tau)=a_{2} \frac{\partial^{2} t_{2}}{\partial x^{2}}(x, \tau), \quad \tau>0, b<x<\infty$

$t_{1}(x, 0)=t_{2}(x, 0)=t_{p}$

$t_{1}(b, \tau)=t_{2}(b, \tau)$

$t_{1}(0, \tau)=t_{o}$

$\lambda_{1} \frac{\partial t_{2}}{\partial x}(+b)=\lambda_{2} \frac{\partial t_{2}}{\partial x}(-b)$

After solving we obtained an accordance $[6,11]$ 


$$
\begin{aligned}
& \frac{t_{2}-t_{p}}{t_{o}}= \\
& =\frac{2 K_{\varepsilon}}{1+K_{\varepsilon}} \sum_{n=1}^{\infty} h^{n-1} \operatorname{erfc}\left(\frac{x-b+(2 n-1) \sqrt{K_{a}} b}{2 \sqrt{a_{2} \tau}}\right) \\
& \frac{t_{1}-t_{p}}{t_{o}}=\operatorname{erfc}\left(\frac{x}{2 \sqrt{a_{1} \tau}}\right)- \\
& -h \sum_{n=1}^{\infty} h^{n-1}\left[\operatorname{erfc}\left(\frac{2 n-x}{2 \sqrt{a_{1} \tau}}\right)-\operatorname{erfc}\left(\frac{2 n b+x}{2 \sqrt{a_{1} \tau}}\right)\right] \\
& \text { where } \quad h=\frac{1-K_{\varepsilon}}{1+K_{\varepsilon}} \\
& K_{a}=\frac{a_{1}}{a_{2}} \text { and } K_{\varepsilon}=\sqrt{\frac{\lambda_{1} c_{p 1} \rho_{1}}{\lambda_{2} c_{p 2} \rho_{2}}}
\end{aligned}
$$

where $a$ - thermal diffusivity, $\mathrm{m}^{2} \cdot \mathrm{s}^{-1} ; c_{p}$ - specific thermal capacity, $\mathrm{J}^{\mathrm{kg}} \mathrm{kg}^{-1} \cdot \mathrm{K}^{-1} ; t$ - temperature of the heated (cooled) body, ${ }^{\circ} \mathrm{C}_{;} t_{0}$ - ambient temperature, ${ }^{\circ} \mathrm{C} ; t_{p}$ - initial temperature of the heated (cooled) body, ${ }^{\circ} \mathrm{C} ; x$ - space coordinate, $\mathrm{m} ; b$ - thickness, $\mathrm{m}$; $\lambda$ - thermal conductivity, $\mathrm{W} \cdot \mathrm{m}^{-1} \cdot \mathrm{K}^{-1} ; \rho$ - density, $\mathrm{kg} \cdot \mathrm{m}^{-3}$; $\tau$ - time, $s ; 1$ - properties of the first layer; 2 - properties of the second layer.

\subsection{Thermal stress of multilayer walls composed of isotropic layers}

The influence of temperature changes on the inhomogeneous, layered plates/shells are generally manifested in two ways. If there is any (even homogeneous) body statically stored indefinitely, preventing the imposition of free thermal expansion of the body, creating a corresponding strain. For multilayer walls thermal stress occurs as a result of the inhomogeneity, when the thermal expansion in equidistant surfaces of walls into the generally different thermal expansion coefficients in the layers.

Consider the generally layer wall, for example the wall with generally variable properties after thick, exposed thermal effects of any temperature profile $\Delta T(x)$, corresponding to a certain point transient of heat transmission of the wall.

Not only the elastic constants, but the coefficient of linear thermal expansion is generally varies discontinuously at the interface of both layers as well as continuously within each of the layers, due to any dependence of these parameters on the temperature [9].

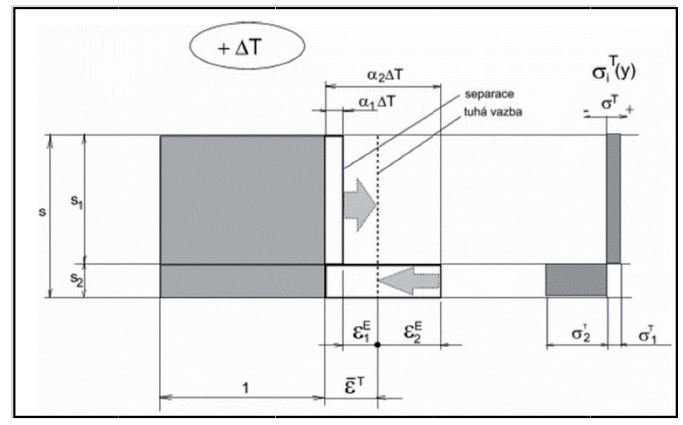

Fig. 2: Thermal stress of multilayer walls.

On the case under consideration as can be seen on the wall as "thinking" composed from an infinite of the number of elementary layers of thickness $d y$. Each layer has its own values of the elastic constants and the thermal expansion coefficient. Value $\Delta T(x)$, express the difference of the actual temperature at the point " $x$ " and reference temperature of the wall, i.e. the temperature at which assume zero stress of the wall.

Let wall is mounted so that it is prevented only warping, while membrane deformation - i.e. a deformation in the direction of the reference plane are enabled. Externally so the wall will show some overall - effective dilatation $\boldsymbol{\varepsilon}^{T}$, assuming of isotropy is the same in both directions of the coordinate system $(y, z)$ of reference plane. The resulting membrane forces in the cross-sections of the wall is equal to zero, then the equation is:

$$
\int_{(s)} \sigma^{T}(x) d x=0 .
$$

If no warping of the wall is the sum of thermal expansion and elastic deformation of each imaginary elemental layer $\mathrm{dx}$ constant, It is equal to the effective value $\boldsymbol{\varepsilon}^{T}$. Considering that it is a equibiaxial stress is:

$\varepsilon^{T}=\frac{\sigma^{T}(x)}{E^{*}(x)}+\alpha(x) \Delta T(x)$.

where: $E^{*}=E /(1-v)$ and $v$ - Poisson number

Using (1) can be expressed in the resulting of unibiaxial deformation of the wall. Equation

$\varepsilon^{T}=\frac{\sum_{k=1}^{2} E_{k}^{*} s_{k} \alpha_{k}}{\sum_{k=1}^{2} E_{k}^{*} s_{k}} \Delta T=\alpha \Delta T$ 
Thermal stress $\sigma_{x}^{T}=\sigma_{z}^{T}$ in the area of the ordinate $y$ will be:

$$
\sigma^{T}(x)=E^{*}(x)\left[\varepsilon^{T}-\alpha(x) \Delta T(x)\right] .
$$

Equation (9) defines stress in the equidistant planes with the plate of plane, except the edges where it is necessary to solve the corresponding boundary value problem. Are not expressed as normal and interlaminar shear stresses which representing the local stress concentrations at the edges of the layers.

\subsection{FEM modeling of transient thermal stress}

Diagrams of shear stresses are plotted in figure 4. Unlike normal interlaminar component the sign peak shear stress does not play any role for subsequent separation of the layers. How to heating and a subsequent rapid cooling the layered structure to cause formation of significant stress peaks, which can cause separation of the layers, applying in the recycling process.

Based on the results of the modeling of transient thermal stress of PCBs is possible to comment on potential uses of these stress for the separation of the $\mathrm{Cu}$ layers in the process of recycling computer waste. The chosen procedure tempering and rapid cooling you can rate depending on the parameters (temperature, residence time) in terms of the level interlinear stress and thus its effectiveness.

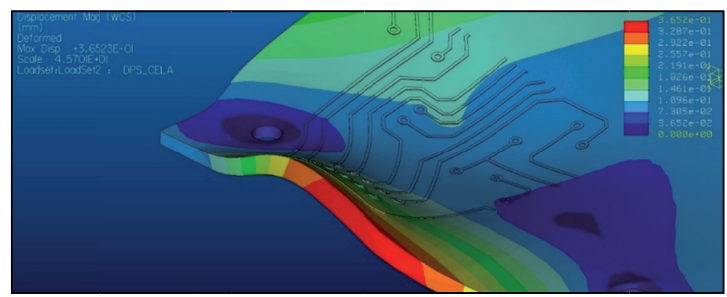

Fig. 3: Thermal stress in the copper path of PCB - deflection depending on temperature.

\section{Experimental Section}

Hot air gun has been use for the most effective heating to $370^{\circ} \mathrm{C}$. The temperature was measured contactlessly using radiometer Thermopoint $64 / 64$ plus, having a range from -30 to $900^{\circ} \mathrm{C}$. The temperature is sufficient even for the separation of a tin. After using mechanical separation components dropped away from the PCB. We used mechanical separation and when you delete the conductive paths. This separation is effective, but in newer types of PCB was necessary for the separation of the copper paths applied more thermal shocks $[5,7]$.

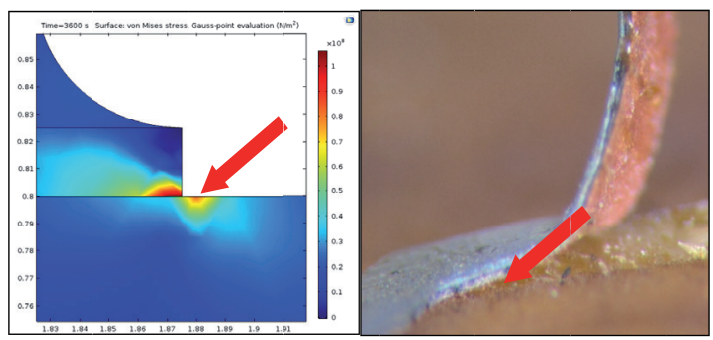

Fig. 4: Pictures of separating copper paths from the PCB from simulation and in the separation in the laboratory.

\section{Results and Discussion}

In our own experiments we have used several methods of heating of the PCB. Heating PCB at a press tempered at $200^{\circ} \mathrm{C}$, further microwave heating. Was the most effective heating with a heat gun to $350^{\circ} \mathrm{C}$. This temperature is sufficient even for the separation of tin, because the melting point of tin is $250^{\circ} \mathrm{C}$. After using mechanical separation, parts dropped away from the PCB. We used a mechanical separation when you delete the conductive paths. Laboratory tests showed that the temperature difference must be much greater than the calculation gives. It is due to the fact, that copper is very plastic and the calculated expansion caused by the temperature difference is smaller than expected. For newer types of PCB it was necessary inject more thermal shocks for the separation of the copper paths. The proposed method of recycling could lead to industrial use, which requires prior diligent sorting of the electric waste.

\section{Conclusions}

The results show that this path of thermal shock separation is feasible because, according to the experiments performed, it was due to different lengths of metal and plastic expansion to tear the copper conductive paths from the PCB. Because PCBs are unfortunately not only double layers but also multilayered, I am waiting for a mathematical model for a multilayer PCB and a proposal for separation. This environmental method of PCD separation could be of great importance in industrial practice.

\section{Acknowledgments}

The research work is supported by the Project of the Structural Funds of the EU, Operational Programme Research and 
Development, Measure 2.2 Transfer of knowledge and technology from research and development into practice and by the Ministry of Education, Youth and Sports of the Czech Republic within the National Sustainability Programme project No. 101303 (MSMT7778/2014) and also by the European Regional Development Fund under the project CEBIA-Tech No. CZ.1.05/2.1.00/03.0089

\section{References and Notes}

[1] Ekoabeceda [Online]. [cit. 2017-02-10]. (in Czech) Available from: http://www.recyklohrani.cz

[2] Recycling [Online]. [cit. 2017-02-10]. (in Czech), Available from: http://ekologie.xf.cz

[3] Beneš, D. Waste, [Online]. [cit. 2017-02-10]. Available from: http://www.waste.cz/pdf/

[4] Noska, M. Gartner: http://computerworld.cz/, (2008)

[5] F. Božek, R. Urban, Z. Zemánek, Recycling, 202 p. (in Czech), ISBN 80-238-9919-8 (2002)

[6] Janáčová, D., Kolomazník, K., Vašek, V., Mokrejš, P. Treatment of electronic waste. 13th WSEAS International Conference on Automatic Control, Modelling and Simulation, ACMOS'11, (2011), ISBN 978-80-227-3081-5

[7] Křenek, J., Janáčová, D., Liška, O., Vašek, V., Šuba, O. Dividing of metal and plastic components of printed circuit boards. 21st International Conference on Circuits, Systems, Communications and Computers (CSCC 2017), The Journal "MATEC Web of Conferences", Crete Island, (2017) ISSN (Electronic Edition): 2261-236X

[8] Lykov, A., B. Teoria teploprovodnosti, (In Russian). Vysšaja škola. Moskva. pp.369. (1967)

[9] Šuba,O., Janáčová, D., Žaludek, M. Modelování transientní teplotní napjatosti. (In Czech). VII. ITC 2009, TOOLS, Zlín. (2009), ISBN 978-80-7318-794.

\section{Biographical notes}

Dagmar Janáčová, prof., Ing., CSc. (1963) Professor, Supervisor of Scientific Projects. Process engineering, Mathematical modeling of manufacturing processes polymers: proteins and plastics recycling, Optimization of processes. Member of the "Information Engineering" Doctoral Studies Program Board, Faculty of Applied Informatics, TBU in Zlin, Member of the University of the Third Age Council, TBU in Zlin, Member of the Ph.D. Studies Program Board: Management of Industrial Systems, HGF,TU, Ostrava, Member of the International Research Teams (ERRC USA, GB BLC) for the Recycling Chromium and Protein from Leather Waste; Supervisor: Prof. Ing. Karel Kolomaznik, M.D., Dr.h.c., Member of the International Programme Committee of the International Carpathian Control Conference - ICCC, Czech Republic - Slovak Republic - Poland - Hungary - Romania., Member of the International Program Committee of the World Scientific and Engineering Academy and Society, 2006-2010, Member of the Program Committee of the Conference on Automation, Control and Processes - ARAP Prague, Czech Republic, Member of the Czech Society of Chemical Engineering, Czech Republic.

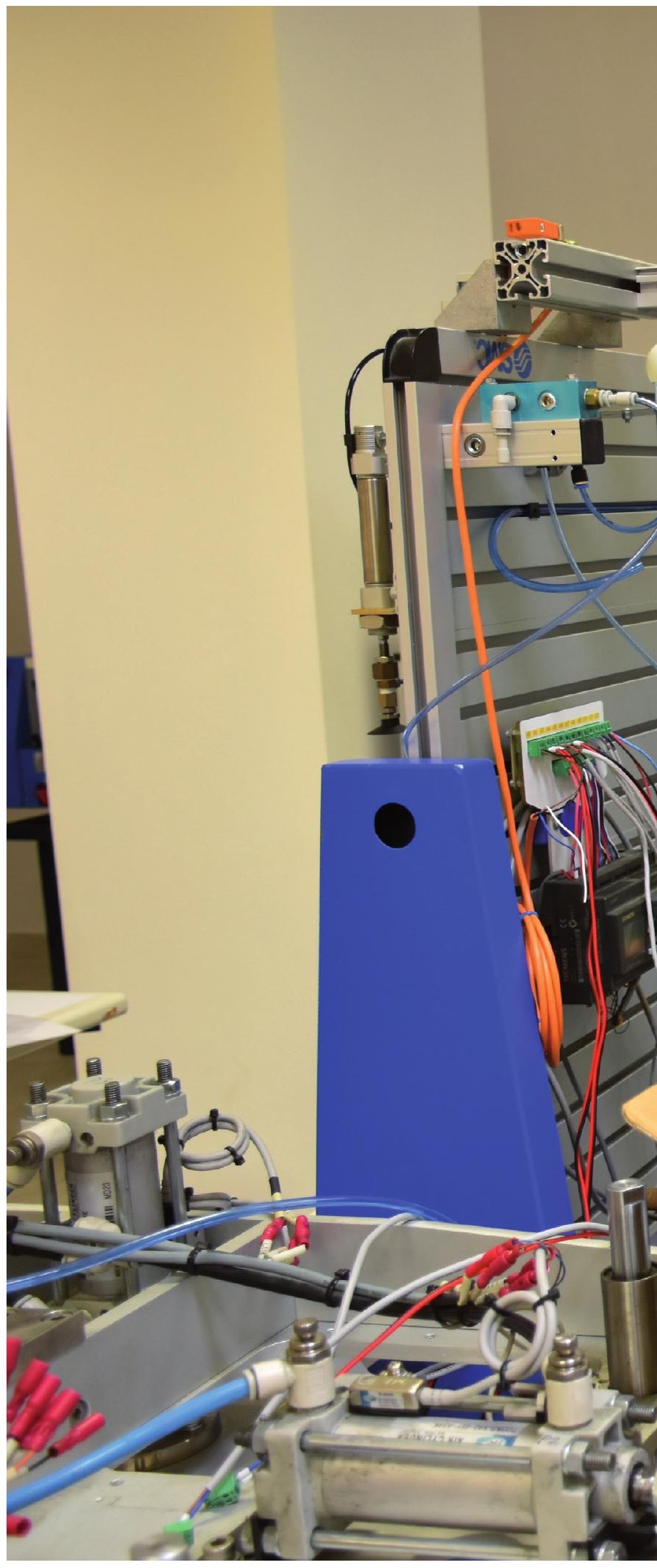

